\title{
Degloving and skin realignments or dorsal dartous flap technique in management of isolated penile torsion in pediatrics
}

\author{
Bassam Kh. Al-Abbasi ${ }^{a}$, Ahmad M. Hamodat ${ }^{b}$ \\ From the ${ }^{a}$ Department of Surgery, Nineveh College of Medicine, University of Mosul, ${ }^{b}$ Al-Khansaa Teaching Hospital, Mosul. \\ Correspondence: Bassam Kh. Al-Abbasi. Department of Surgery, Nineveh College of Medicine, University of Mosul, Mosul, \\ Iraq. Email: bassamalabbasi@yahoo.com.
}

(Ann Coll Med Mosul 2013; 39 (1): 89-93).

Received: $13^{\text {th }}$ Jun. 2012; Accepted: $4^{\text {th }}$ Mar. 2013.

\section{ABSTRACT}

Objective: To evaluate the proper technique used for management of penile torsion in pediatrics in relation to degree of torsion.

Patients and methods: From February 2008 to December 2010, 54 patients were assessed for the degree of penile torsion at pediatric surgery center at Al-Khansaa Teaching Hospital in Mosul. The angle of torsion was assessed using a digital photograph of the penis and classified into three grades, Mild with 15 - 30 degree angle of torsion, moderate with 45-90 degree angle of torsion and sever with 100-170 degree angle of torsion.

Two techniques were used for repairing the torsion, the degloving and skin realignment technique for the mild condition and dorsal dartous flap technique for the moderate and severe types. All operations were done as a day case procedure. No catheter used.

Results: Forty five patients (83\%) were discovered accidentally while assessing for circumcision or other problems, 30 patients $(55 \%)$ were in the first year of life, 50 patients $(93 \%)$ have a counter clock wise direction of torsion (to the left) while only 4 patients $(7 \%)$ have a clockwise direction (to the right). Thirty five patients $(65 \%)$ classified as mild torsion, while 16 patients $(29.5 \%)$ have moderate degree of torsion and only 3 patients $(5.5 \%)$ severe degree. Degloving and realignment of skin were used for the mild condition in 35 patients $(65 \%)$ while dorsal dartous flap technique was confined for moderate $(29.5 \%)$ and both procedures used for severe type patients $(5.5 \%)$.

Conclusion: Simple realignment technique during circumcision was enough to manage the mild degree, while in severe degree, dorsal dartous flap rotation seems to be more effective. There were no complications, and good cosmetic results were obtained.

Keywords: Penile torsion, degloving, dorsal dartous flap.

\section{تقنية لحب الجلد وإعادة ترتيبه أو جلد ظهري (Dorsal dartous flap)



$$
\text { الهُف: لتحديد الطريقة المناسبة المستخدمة لعلاج إلتواء القضيب عند الأطفال حسب درجة الإلى الإلتواء. }
$$

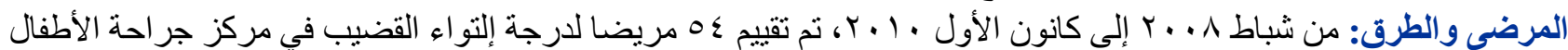

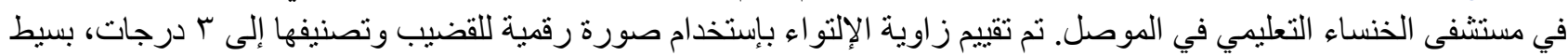





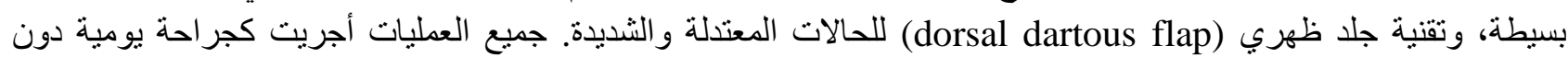



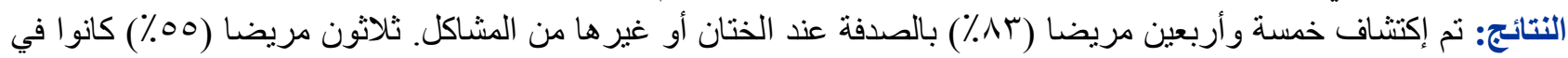

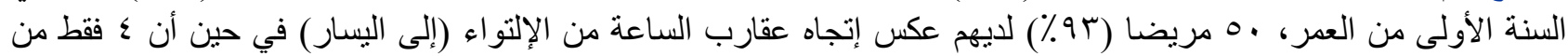




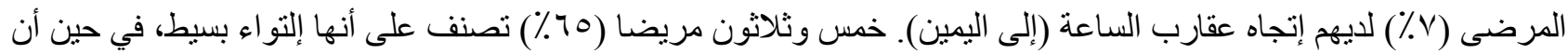

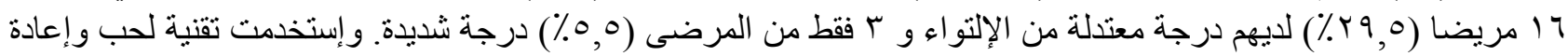

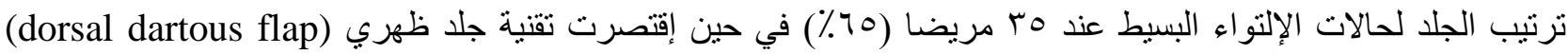

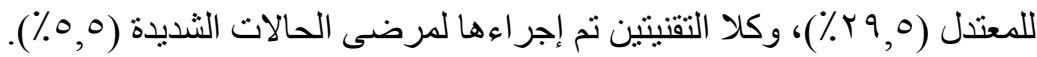



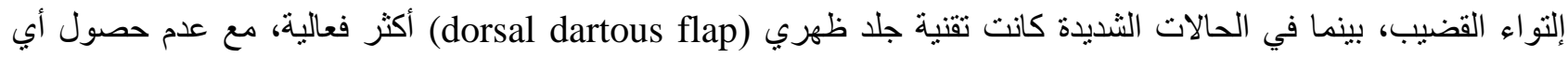
مضاعفات ونتائج تجميلية جيدة.

$\mathrm{P}$ enile torsion is an axial rotational defect of the penile shaft ${ }^{(1,2)}$. It's usually in the counter clockwise direction, that is to the left side ${ }^{(3,4)}$.

The true incidence of penile torsion is not known and it is not a very common deformity ${ }^{(5)}$.

Few data exist in the literature about penile torsion and the exact etiology is unclear ${ }^{(6-9)}$.

It can be seen independently or in association with other penile anomalies such as hypospadias or chordee ${ }^{(1,4)}$.

Some authors believe that the primary defect is due to abnormal skin attachment, others believe that it is caused by asymmetrical development of corpora cavernosa ${ }^{(6)}$.

In 1992 Slawin and Neglar described a technique of removing an ellipse of corporal tissue to correct torsion ${ }^{(10)}$. In 2000 Bolgrano et al used modified Nesbit teqnique (asymmetric tunica albuginea excision ${ }^{(11)}$. In 2004 Fisher and Parker described a technique using dorsal dartous flap rotation ${ }^{(12)}$. In 2009 Brent described a new technique for penile torsion correction using diagonal corporal plication suture $^{(4)}$.

To date this was the first study dealing with the problem of penile torsion in Mosul city, our aim of this study is to evaluate penile torsion in pediatrics and the proper surgical techniques used for correction in relation to degree of torsion in comparison with other literatures.

\section{PATIENTS AND METHODS}

From February 2008 to December 2010; 54 boys with isolated penile torsion were prospectively evaluated and operated upon in pediatric surgery center at Al- Khansaa Teaching Hospital, their age ranging between 1-10 years.

Most of these boys discovered accidentally at time of circumcision, others presented in association with other problems, abnormal shape and urinary stream noticed by parents or post circumcision.
The angle of torsion (degree) was assessed on digital photography of the penis using AutoCAD program used by the architectures on A-P view depends on 2- land marks, the slit of the meatus in relation to scrotal median raphee (Fig.1), and according to that our patients classified into three grades of torsion:

1. Mild with15-30 degree.

2. Moderate with $45-90$ degree.

3. Severe with 100-170 degree.

Operations were done by two surgeons (the authors). Two techniques were used (based on surgeon preference) for correction of torsion depending on the degree of torsion and angle of rotation. Degloving of the penile skin by dividing the adhesions along the entire penile shaft, and repositioning the skin bringing the twisted median raphee to its straight direction for mild degree (1530).

The dorsal dartous flap technique was used for the moderate and severe degree, in which the dartous flap after its dissection from the dorsal penile skin, was rotated around the side of the penile shaft opposite to the direction of rotation and attached to its ventral aspect, this creates a rotational force that counterbalance that of penile torsion (Fig. 2).

Assessment for corrective criteria done per operatively by noticing the slit of the urethral meatus in one line with the scrotal raphee (Fig. 3).

All procedures were done as day cases, no complications were recorded and no catheter used during both procedures.

All our patients were followed for about one year.

\section{RESULTS}

Forty five patients (83\%) were discovered accidentally while assessing for circumcision or other problems (inguinal hernia, hydrocele and undescended testes), while only seven patients $(13 \%)$ with moderate and severe degree were 
referred because of abnormal shape of penis and/ or urinary stream direction. Two patients (4\%) presented post circumcision.

Thirty patients (55\%) were in the first year of life, 15 patients between 1-2 years and 9 patients were 4-10 years of age.

Fifty patients (93\%) with counter clockwise direction of rotation (to the left), and only four patients $(7 \%)$ with clockwise rotation (to the right).

Mild rotation found in 35 patients (65\%), 16 with moderate rotation $(29.5 \%)$, and 3 with severe degree of rotation $(5.5 \%)$.

Degloving and skin realignment were used for correction of mild degree in 35 patients, while dorsal dartous flap technique was used for moderate degree in 16 patients, both techniques were combined to correct three patients with severe degree of torsion to achieve full correction of the rotation (Table 1).


Figure 1 \& 2. Severe penile torsion with 131 degree torsion using auto CAD program.

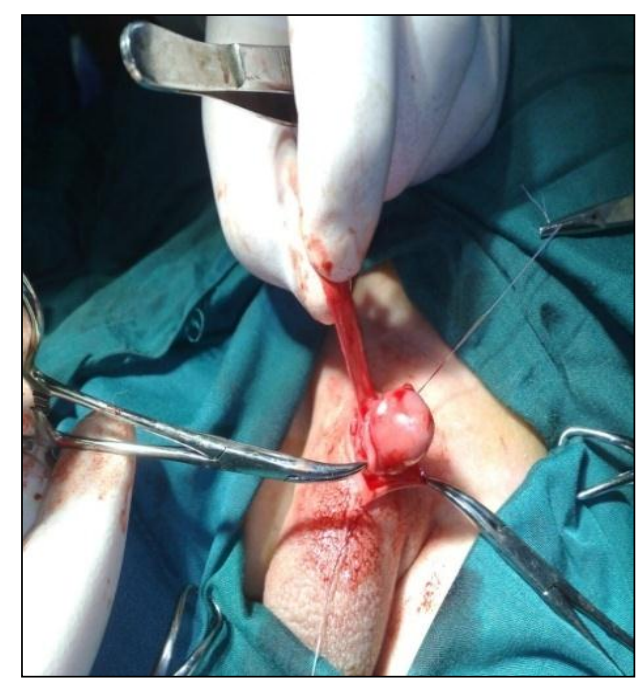

Figure 3. Creation of dartuos flap.

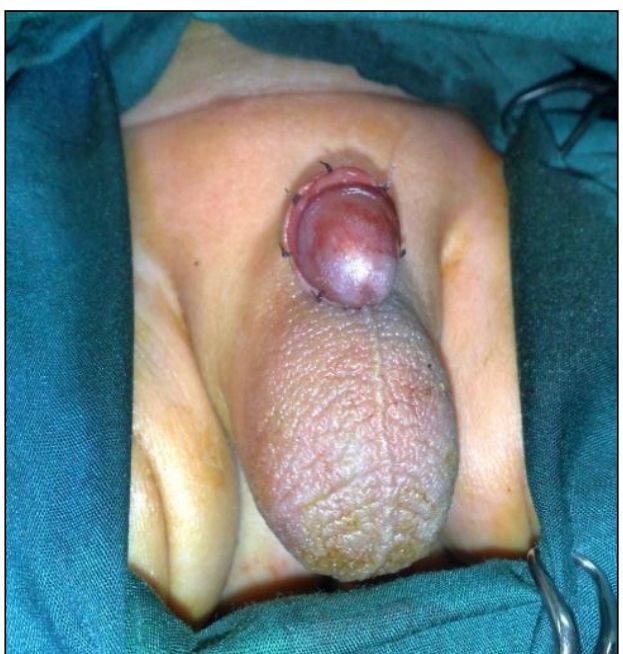

Figure 4. Post correction appearance (meatal slit and median raphee in one line)

Table 1. Degree of torsion and procedures used for each.

\begin{tabular}{|c|c|c|c|}
\hline $\begin{array}{c}\text { Degree of } \\
\text { torsion }\end{array}$ & No. & Technique & $\%$ \\
\hline Mild (15-30) & 35 & $\begin{array}{c}\text { Degloving \& skin } \\
\text { realignment }\end{array}$ & $65 \%$ \\
\hline $\begin{array}{c}\text { Moderate } \\
(45-90)\end{array}$ & 16 & $\begin{array}{c}\text { Dorsal dartous } \\
\text { flap }\end{array}$ & $29 \%$ \\
\hline $\begin{array}{c}\text { Severe } \\
(100-170)\end{array}$ & 3 & Combined & $5.5 \%$ \\
\hline Total & 54 & & $100 \%$ \\
\hline
\end{tabular}

\section{DISCUSSION}

Penile torsion is a rare anomaly specially when isolated. On reviewing the published reports of the penile torsion repair in the last three decades, it 
was very low both in number of the reports and number of cases included in these reports ${ }^{(5,13,14)}$.

We report 54 cases of different grades which is regarded as large series in comparison to others, Ashraf Hussain et al reported 13 boys with isolated penile torsion over two years duration ${ }^{(9)}$, while Abou Zied et al reported 19 boys with hypospadias associated with penile torsion over 1.5 years ${ }^{(1)}$, Lizhou et al in 2006 described his technique for correction of penile torsion on 17 boys ${ }^{(6)}$.

This difference in reporting this problem might be attributed to under diagnosis of this mild asymptomatic condition, because most of the paramedical staff and some surgeons are not familiar with this problem. This is supported in our study because $83 \%$ of our cases were diagnosed accidentally on clinical examination preceding circumcision and we believe that if the parents, medical, and paramedical staff (who use to do circumcision in the hospital or clinics) were aware of penile torsion, the number of cases might be more.

Torsion of penis can vary in severity ranging from 30 degree in mild cases to 180 degree in severe cases ${ }^{(15)}$, it can be caused by abnormal skin attachment ${ }^{(1)}$, however that might not be the only causative actor since torsion is not always corrected by penile degloving ${ }^{(16)}$. These facts are proofed in our study and other studies since 35\% of our patients with moderates and severe degree of torsion corrected by dartous flaps while those with mild torsion (65\%) were corrected with skin realignment technique alone this confirm that there are other causative factors play a role in the etiology other than abnormal skin attachment.

In most reports the methods of measuring the degree of torsion is not clarified, Pierrot and Mutharagan described a method using sterile small protractor with modification for better adjustment (7), Abou Zied et al measured the angle of rotation on a digital photograph of the penis using software program used by the radiologist for image analysis which can be applied pre and post operatively and provides an objective evaluation for the corrective surgery ${ }^{(1)}$.

In our center we don't have such program, but instead of that we used the AutoCAD program that is used by the architectures to measure and assess the angle of rotation which applied on a digital photograph pre and post operatively (Fig.
1\&2). In addition to that we depended on two landmarks to assess the results of corrective surgery per operatively, in which the long axis of the meatal slit became in same line with the scrotal median raphee, this will provide an excellent intraoperative sign of full correction (Fig. 4).

Congenital penile torsion is a benign condition which my need no treatment especially for its mild conditions $^{(17)}$. In our locality circumcision is done routinely for religious purposes and we use to assess every patient who underwent circumcision for any abnormality including penile torsion and if it is present we take the permission from the parents for correction, that's why all patients even with mild degree torsion corrected at time of circumcision.

In our study we applied the degloving and skin reattachment technique for $65 \%$ with mild degree with $100 \%$ correction and no complications, this agrees with most authors who described this technique to be only effective for mild form of penile torsion ${ }^{(6,12,17)}$. However Tryfonas et al reported satisfactory result by applying this technique for more severe degree by suturing the skin in an over corrected position ${ }^{(18) .}$

The dorsal dartous flap has been widely used by the urologist to cover their urethroplasty. In 2004 Fisher and Parker described this technique to correct counterclockwise penile torsion ${ }^{(12)}$. We found this technique very effective in correcting moderate to severe degree of torsion. We observed its effect in correcting penile torsion and covering the urethroplasty in Snodgrass technique for hypospadias repair applied on our patients, and from this observation we started to manage moderate and severe types of isolated penile torsion and rotating the flap around the side of penile shaft opposite to the direction of torsion in $35 \%$ of patients.

Dorsal dartous flap technique provided $80 \%$ correction in Abuo Zied series ${ }^{(1)}$, and $100 \%$ in Fisher and Park series ${ }^{(12)}$, while only $64 \%$ achieved complete resolution of penile torsion in the series of Bauer and Kogan in $2009^{(19)}$.

In our study we recorded $100 \%$ correction in both techniques, but we combined both techniques in managing severe degree of penile torsion to reach $100 \%$ correction. This difference in success rate might be related to technical application of the procedures in relation to degree of torsion. 
However to avoid the risk of under or over correction the amount of flap rotation should be determined with respect to degree of torsion and still some final adjustment should be made during skin closure to gain high success rate ${ }^{(1)}$.

\section{CONCLUSION}

Isolated penile torsion is not a rare problem. Preoperative assessment and measuring the angle of rotation is valuable to decide the proper technique for correction.

Simple degloving and skin realignment is very effective in managing mild degree at time of circumcision; while dorsal dartous flap rotation is more suitable for moderate and severe degree. Sometimes combination of both procedures gives $100 \%$ correction in severe condition, with no complications and good cosmetic results.

\section{REFERENCES}

1. Abou Zeid A, Soliman H. Penile torsion: an over looked anomalies with distal hypospadias. Annals Pediatr. Surg. 2010;6:93-97.

2. Patrick J, John M. Abnormalities of the urethra, penis and scrotum. In Jay L, James A, Arnold G, Eric W. editors. Pediatric surgery. Sixth edition. MOSBY Elsevier 2006.p.1899-1908.

3. Jack S. Penile torsion. In: David F, John P, Howard M. editors. Operative pediatric urology. Second edition. Churchill Livingstone; 2002. p. 275-285.

4. Brent W. Penile torsion correction by diagonal corporal placation sutures. International Braz $\mathrm{J}$ Urol. 2009;35(1):56-59.

5. Redman IF, Bissada NK. One stage correction of chordee and 180 - degree penile torsion. Urology. 1976;7:632-3.
6. Zhou L, Mei H, Hwang AH, Xie H, Hardy BE. Penile torsion repaire by suturing tunica albuginea to the pubic periostium. J Pediat. Surg. 2006; 41:E7-9.

7. Pierrot S, Muthuragan S. Incidance and predictive factors of isolated neonatal penile glanular torsion. $J$ Pediatr Urol 2007; 3:495-9.

8. Bar Yousef $\mathrm{Y}$, Binyamini J, Matzkin H, et al .Degloving and realignment -simple repair for isolated penile torsion. Urology 2007;69:369-71.

9. Hussain A, Nagib I. Penile degloving and skin reattachment technique for repaire of penile torsion, our experience. Egypt J. Plast. Reconstr. Surg. 2007;31(1): 19-23.

10. Slawin KM, Nagler HM. Treatment of congenital penile curvature with penile torsion: A new twist. J Urol.1992;147(1):152.

11. Belgrano E, Linguori G, Trombeta C, Siracusano S. Correction of complex penile deformities by modified Nesbit procedure, asymmetric tunica albuginea excision. Eur. Urol. 2000;38(2):172-6.

12. Fisher $C$, Parker $M$. Penile torsion repair using dorsal dartous flap rotation. J Urol. 2004;17(5):1903.

13. Azmy A, Eckstein H.B. Surgical correction of tortion of the penis. Br. J Urol. 1981; 53 (4):378.

14. Culp O S. Struggle and triumphs with hypospadias and associated anomalies :review of 400 cases. J Urol. 1996;96(3):339.

15. Shaeer $O$. Torsion of the penis in adults: prevalence and surgical correction. .J Sex Med 2008;5:735.

16. Bhat A, Bhat MP, Saxena G. Correction of penile torsion by mobilization of urethral plate and urethra. J Pediatr. Urol. 2009;5:451-457.

17. Elder JS. Anomalies of the genitalia in boys and their surgical management. In: Wein AJ. Campbelle Walsh Urology $9^{\text {th }}$ edition. W. B. Saunders; 2007.p. 3754-60.

18. Tryphonas GI, Klokkaris $A$, Sveromis $M$, et al. Torsion of penis: a comparative study between two procedures of skin derotation. Pediat. Surg. Int. 1995;10: 359-61.

19. Bauer R, Kogan BA. Modern technique for penile torsion repair. J Urol. 2009;182:286-91. 